\title{
Intracavernous injection of prostaglandin E1 in spinal cord injured patients with erectile dysfunction. A preliminary report
}

\author{
SFT Tang, NK Chu and MK Wong \\ Department of Rehabilitation Medicine, Chang Gung Memorial Hospital, 199 Tung Hwa North Road, Taipei, \\ Taiwan, Republic of China
}

\begin{abstract}
Our experience with intracavernous injection of prostaglandin E1 in spinal cord injured patients with neurogenic erectile dysfunction included 15 men. They received testing dosage starting from $5 \mu \mathrm{g}$ with increasing dosage (maximum $20 \mu \mathrm{g}$ ) to achieve a rigid erection of Schramek's grade 5 and lasting for at least $20 \mathrm{~min}$. All of them had achieved functional erection adequate for coitus after treatment except one patient who had been proved to have venogenic impotence. We found that intracavernous injection of prostaglandin E1 had significantly improved the erectile condition. No systemic side effect or any other complication was noted except that pain at the injection site was complained of in two patients with incomplete lesion.
\end{abstract}

Keywords: spinal cord injury; erectile dysfunction; intracavernous prostaglandin E1 injection

\begin{abstract}
Introduction
Intracavernous vasoactive agents have revolutionised the diagnosis and treatment of impotence since the introduction of papaverine, a smooth muscle relaxant, by Virag ${ }^{1}$ and phentolamine, an alpha-adrenergic antagonist, by Brindley. ${ }^{2}$ Use of a combination of these agents for the therapeutic intracavernous injection for the treatment of erectile dysfunction was preferred at many centres in the early 1980s because it is effective and the dose of papaverine is low. However, injection of this solution is associated with an incidence of complications such as priapism, nodularity, induration and fibrosis. ${ }^{3-5}$ Prostaglandin E1 has begun to be used as an option for treatment after Ishii et al presented the first report of its efficacy and the low risk of priapism. ${ }^{6}$ Intracavernous pharmacotherapy has been previously reported for spinal cord injured patients but few data are available concerning the management of erectile dysfunction in such patients with intracavernous prostaglandin $\mathrm{E} 1$ injection. ${ }^{7-9}$ We performed a study by using clinical measurements to compare the erectile condition in chronic spinal cord injured patients who had received intracavernous prostaglandin $\mathrm{E} 1$ injection therapy. Also any complications and the follow-up for ejaculation were considered.
\end{abstract}

\section{Patients and methods}

Fifteen male chronic spinal cord injured (SCI) patients were included for the application of the intracavernous injection of prostaglandin E1 for the management of erectile dysfunction since May 1991. Their age ranged from 25 to 50 years, with an average age of 38.5 years.
All of the patients had normal sexual activity before being injured, but erectile dysfunction and absence of ejaculation were noted after the SCI. The average interval from the injury was 6.3 years. Among these patients, eight had an injury at the lumbar level, six the thoracic, and one at the cervical level. Incomplete lesions were found in eight patients. The patients had all been identified with neurogenic erectile dysfunction after clinical assessment and psychological evaluation. They also underwent penile doppler ultrasonography to rule out arteriogenic erectile dysfunction. The erectile condition of the patients was evaluated with Schramek's grading (Table 1). ${ }^{10}$

Patients received testing doses of an intracavernous injection of prostaglandin E1, starting at $0.5 \mu \mathrm{g}$ with increasing dosage to achieve a rigid erection of grade 5 and lasting for at least 20 min (a maximum dosage of $20 \mu \mathrm{g}$ would be applied). The blood pressure and the brachial pulse were monitored before and after the intracavernous injection in all of the patients. They were instructed in self-injection (or their partners were instructed) and they were allowed to continue the regimen at home once the appropriate dosage and injection technique were achieved. The maximum recommended injection frequency was twice a week.

Table 1 Grade of erection ${ }^{10}$

\begin{tabular}{ll}
\hline Grade 1 & No erection \\
Grade 2 & Slight tumescence \\
Grade 3 & Full volume without rigidity \\
Grade 4 & Sufficient for sexual intercourse \\
Grade 5 & Full erection
\end{tabular}


The patients were told to return to hospital if the erection lasted for more than $6 \mathrm{~h}$.

All of the patients were followed up regularly in the outpatient clinic for any fibrosis or plaque formation in the penis and for any other complication. They were asked to return to the outpatient clinic twice per month initially for three months, and then once per month. The average follow-up period was 1.6 years and any change in dosage, and the condition of the ejaculation were evaluated.

\section{Results}

The patients' preinjection erection was induced by a sexual video and by masturbation. The erectile condition of eight patients were defined as grade 1 , one as grade 2 , two as grade 3 , and four patients with grade 4 and grade 5 had full but unsustained erection before the treatment (Table 2). All of them had achieved grade 5 functional erections adequate for coitus at the end of test dosing except for one patient who had only a grade 2 erection despite receiving a maximum dosage (Table 2). Venous leakage was proved later in this case with cavernosography. His penile erection was adequately sustained with vacuum tumescence constriction therapy.

The erectile condition in Schramek's grading of posttreatment was found to be significantly higher than that of pre-treatment by the non-parametric Wilcoxon Sign Rank test $(P<0.001)$, but no significant dosage effect of prostaglandin E1 was found in the difference between pre-treatment and post-treatment in the Schramek grading (Table 3). The duration of erection ranged from 20 to $120 \mathrm{~min}$, with the average of $59.1 \mathrm{~min}$

Table 2 Patient description and results of treatment

\begin{tabular}{|c|c|c|c|c|c|c|}
\hline Patient & $\begin{array}{l}\text { Neurological } \\
\text { level }\end{array}$ & $\begin{array}{c}\text { Pre-injection } \\
\text { Schramek } \\
\text { grading }\end{array}$ & $\begin{array}{c}\text { PGE1 } \\
\text { dosage } \\
(\mu g)\end{array}$ & $\begin{array}{c}\text { Post-injection } \\
\text { Schramek } \\
\text { grading }\end{array}$ & $\begin{array}{l}\text { Duration of } \\
\text { erection } \\
\text { (min) }\end{array}$ & Ejaculation \\
\hline 1 & T4 IC & $5^{\mathrm{a}}$ & 15 & 5 & 30 & + \\
\hline 2 & $\mathrm{~L} 4 \mathrm{IC}^{\mathrm{b}}$ & $5^{a}$ & 20 & 5 & 40 & + \\
\hline 3 & L3 IC & 2 & 10 & 5 & 120 & + \\
\hline 4 & $\mathrm{~T} 12 \mathrm{CP}$ & 1 & 10 & 5 & 40 & - \\
\hline 5 & L5 IC & 1 & 20 & 5 & 120 & + \\
\hline 6 & $\mathrm{~T} 12 \mathrm{CP}$ & 1 & 15 & 5 & 50 & - \\
\hline 7 & $\mathrm{~T} 12 \mathrm{CP}$ & 1 & 15 & 5 & 40 & - \\
\hline 8 & $\mathrm{~T} 12 \mathrm{CP}^{\mathrm{d}}$ & 1 & 20 & 2 & - & - \\
\hline 9 & L1 CP & 3 & 20 & 5 & 20 & - \\
\hline 10 & $\mathrm{~T} 12 \mathrm{CP}$ & 1 & 20 & 5 & 25 & - \\
\hline 11 & L1 CP & $4^{a}$ & 15 & 5 & 43 & + \\
\hline 12 & L3 IC & 3 & 15 & 5 & 120 & + \\
\hline 13 & $\mathrm{~L} 5 \mathrm{IC}^{\mathrm{c}}$ & 1 & 20 & 5 & 30 & + \\
\hline 14 & L3 IC & 1 & 15 & 5 & 120 & Not known \\
\hline 15 & C5 IC & $5^{a}$ & 15 & 5 & 30 & + \\
\hline
\end{tabular}

IC: incomplete SCI; CP: complete SCI; afull erection but unsustained; ${ }^{b}$ pregnancy of partner noted; ${ }^{c}$ pain at injection site; ${ }^{\mathrm{d}}$ venous leakage by cavernosography

Table 3 Comparing Schramek grading of pre-injection erection versus post injection erection: total and by prostaglandin E1 dosage

\begin{tabular}{|c|c|c|c|c|}
\hline \multirow{2}{*}{$\begin{array}{l}\text { PGE1 } \\
\text { dosage } \\
(\mu g)\end{array}$} & \multirow[t]{2}{*}{$n$} & \multicolumn{3}{|c|}{ Erectile-Schramek grading: medium (minimum, maximum) } \\
\hline & & Pre-injection & Post-injection & Difference $=$ Post - Pre \\
\hline 10 & 2 & $\begin{array}{c}1.50 \\
(1.0,2.0)\end{array}$ & $\begin{array}{c}5.0 \\
(5.0,5.0)\end{array}$ & $\begin{array}{c}3.5 \\
(3.0,4.0)\end{array}$ \\
\hline 15 & 7 & $\begin{array}{c}3.0 \\
(1.0,4.5)\end{array}$ & $\begin{array}{c}5.0 \\
(5.0,5.0)\end{array}$ & $\begin{array}{c}2.0 \\
(0.5,4.0)\end{array}$ \\
\hline 20 & 6 & $\begin{array}{c}1.0 \\
(1.0,4.5)\end{array}$ & $\begin{array}{c}5.0 \\
(2.0,5.0)\end{array}$ & $\begin{array}{c}3.0 \\
(0.5,4.0)\end{array}$ \\
\hline Total & 15 & $\begin{array}{c}1.0 \\
(1.0,4.5)\end{array}$ & $\begin{array}{c}5.0 \\
(2.0,5.0)\end{array}$ & $\begin{array}{c}3.0 \\
(0.5,4.0)\end{array}$ \\
\hline
\end{tabular}

Overall, the erectile grading of post-injection was found to be significantly higher than that of the pre-injection by non-parametric Wilcoxon sign rank test $(P<0.001)$

No significant PGE1 dosage effect was found on the difference between post- $v s$ pre-injection erectile grading by non-parametric Kruskall-Wallis test $\left(\chi^{2}=0.614, P=0.73\right)$ 
after treatment (Table 2). Eight patients were noted to have ejaculation (Table 2 ). But no significant influence was found among the three prostaglandin E1 dosage levels in the percentage of ejaculation by generalized estimation equation modelling $(Z=4.10, P<0.001)$. More excitingly, the partner of an incomplete L4 cord injured patient (patient 2) became pregnant after the second self-injection at home.

The alteration of the systolic and diastolic blood pressures measured before and after the intracavernous injection were within $12.0 \mathrm{~mm} \mathrm{Hg}$ and $10.5 \mathrm{~mm} \mathrm{Hg}$ respectively. The average frequency change of the brachial pulse was $8.6 \mathrm{~min}^{-1}$. No systemic side effects or any other complication was noted in the patients after the intracavernous prostaglandin E1 injection except pain at the injection site, complained of in two patients with incomplete neurological lesions.

\section{Discussion}

Although many men with spinal cord injuries retain the capacity for penile erection, those with high lesions are likely to exhibit reflex erections, and those with low lesions may have a psychogenic or a reflex erection. Those with an incomplete lesion are most likely to have sparing of erection; many of the patients cannot achieve coitus due to an inadequate or a poorly sustained erection. ${ }^{11}$ Successful sexual intercourse was noted in only $20-30 \%$ of cord injured patients. ${ }^{9}$ Moreover, only $5-18 \%$ of those patients had true ejaculation. ${ }^{12}$ There is currently increasing evidence that prostaglandin E1 is presently an effective agent for intracavernous injection therapy, and there appears to be a low incidence of corporeal fibrosis, of prolonged erection or of systemic reactions associated with its use. ${ }^{13}$ Several studies using a subjective evaluation have shown that prostaglandin E1 is more effective than a combination of papaverine and phentolamine, and it has also been found to be extremely effective as a single agent. $^{13,14}$

In our study, 14 patients $(93.3 \%)$ have achieved a grade 5 functional erection, and the average duration was $59.1 \mathrm{~min}$. These results are consistent with the reports by Waldhauser ${ }^{15}$ and Ishii. ${ }^{14}$ Ejaculation was noted in eight patients, and pregnancy was noted in the partner of one patient. It appears that the intracavernous injection of prostaglandin E1 is not only of significant benefit for penile erection, but also for ejaculation in spinal cord injured patients, and is worth further study. No systemic side effect or any complication was noted in our patients after intracavernous injection therapy, which is consistent with several reports. ${ }^{14,15}$ Only two patients complained of discomfort at the injection site, and this is also an encouraging finding in comparison with another report. ${ }^{10}$ In the near future we are going to apply the Rigiscan for the quantitative assessment of the effect of intracavernous prostaglandin E1 injection for penile tumescence and rigidity in order to investigate the dosage response and the erectile pattern in spinal cord injured patients.

\section{Acknowledgements}

The authors would like to thank Chuan-Chuan C Wun, Assistant Professor in the Department of Biometry, School of Public Health, University of Texas Health Science Center, Houston, TX for statistical assistance.

\section{References}

1 Virag R. Intracavernous injection of papaverine for erectile failure. Lancet 1982; 2: 938.

2 Brindley GS. Cavernosal alpha-blockade: a new technique for investigating and treating erectile impotence. $\mathrm{Br} \mathrm{J}$ Psychiatry 1983; 143: 332

3 Girdley FM et al. Intracavernous self-injection for impotence: a long term therapeutic option? Experience in 78 patients. $J$ Urol 1988; 140: 972-974.

4 Lakin MM et al. Intracavernous injection therapy: analysis of results and complications. J Urol 1990; 143: 1138-1141.

5 Levine SB et al. Side effects of self-administration of intracavernous papaverine and phentolamine for treatment of impotence. J Urol 1989; 141: 54-57.

6 Ishii $\mathrm{N}$ et al. Studies on male sexual impotence. Report 18. Therapeutic trial with prostaglandin E1 for organic impotence. Jpn J Urol 1986; 77: 954.

7 Bodner DR et al. The application of intracavernous injection of vasoactive medications for erection in men with SCI. J Urol 1987; 138: 310-311.

8 Sidi AA et al. Vasoactive intracavernous pharmacotherapy for the treatment of erectile impotence in men with SCI. J Urol 1987; 138: 539-542.

9 Lloyd LK et al. Intracavernous pharmacotherapy for management of erectile dysfunction in SCI. Paraplegia 1989; 27: 457-464.

10 Schramek $\mathrm{P}$ et al. Prostaglandin E1 in erectile dysfunction. Efficiency and incidence of priapism. Br J Urol 1990; 65: 68-71.

11 Somers MF. Sexuality and sexual functioning. In: Somers MF (ed). Spinal Cord Injury Functional Rehabilitation, 1st edn. Appleton \& Lange: Connecticut 1992; p 281.

12 Linsenmeyer TA. Infertility in men with spinal cord injury. Arch Phys Med Rehabil 1991; 72: 747-753.

13 Allen RP et al. Objective double-blind evaluation of erectile function with intracorporeal papaverine in combination with phentolamine and/or prostaglandin E1. J Urol 1992; 148: $1181-1183$.

14 Ishii $\mathrm{N}$ et al. Intracavernous injection of prostaglandin E1 for the treatment of erectile impotence. J Urol 1989; 141: 323-325.

15 Waldhauser $\mathrm{M}$ et al. Efficiency and side effects of prostaglandin E1 in the treatment of erectile dysfunction. J Urol 1988; 140: $525-527$. 